\title{
Choosing Wisely Neurology: Recommendations for the Canadian Neurological Society
}

\author{
Catherine Beyak, Fiona Costello, Jodie M. Burton, Philippe Couillard
}

\begin{abstract}
Background: Choosing Wisely Canada (CWC) is a national branch of a global campaign advocating for fewer unnecessary tests and for optimizing patient care. Professional societies representing physicians, pharmacists, and nurses participate by generating lists of recommendations meant to reduce patient harm and resource mismanagement in healthcare. The Canadian Neurological Society (CNS) plays an important role in advocating for quality patient care demonstrated by deriving specific recommendations. This process is described. Method: The CNS Choosing Wisely task force adapted 10 recommendations for Canadian neurology practice. These were approved by the CNS board, and subsequently ranked by CNS members. Results: Ten recommendations were brought forward and ranked in a survey completed by CNS members. Survey ranking is presented. The top five recommendations were selected and optimized, resulting in seven key recommendations. Conclusion: The recommendations set forth by the CNS will help with resource stewardship and patient safety in the delivery of neurological care by healthcare providers in Canada.
\end{abstract}

RÉSUMÉ : Recommandations du volet neurologique de la campagne Choisir avec soin destinées à la Société canadienne de neurologie. Contexte : Choisir avec soin au Canada est le pendant national d'une campagne mondiale prônant la réduction des tests inutiles et l'optimisation des soins prodigués aux patients. Des regroupements professionnels représentant des médecins, des pharmaciens et des infirmières y participent en formulant une liste de recommandations visant à réduire les préjudices causés aux patients et la mauvaise gestion des ressources dans le domaine des soins de santé. La Société canadienne de neurologie $(\mathrm{SCN})$ joue à cet égard un rôle important en plaidant pour des soins de qualité et en émettant des recommandations spécifiques. C'est ce processus que nous entendons décrire ici. Méthode : Le groupe de travail Choisir avec soin de la SCN a adopté dix recommandations en lien avec la pratique neurologique au Canada. Ces recommandations ont été approuvées par le conseil d'administration de la SCN et subséquemment classées par les membres de la SCN. Résultats : Comme nous l'avons dit, dix recommandations ont été formulées et ensuite classées dans le cadre d'un sondage complété par les membres de la SCN. C'est ce classement que nous voulons présenter. À noter que cinq principales recommandations ont été adoptées pour être ensuite élargies, ce qui a entraîné en bout de ligne la formulation de sept recommandations clés. Conclusion : Les recommandations mises de l'avant par la SCN contribueront à une meilleure gestion des ressources et à la sécurité des patients bénéficiant au Canada de soins neurologiques.

Keywords: General neurology, Quality of care, Guidelines, Canadian Neurological Society

doi:10.1017/cjn.2020.210

Can J Neurol Sci. 2021; 48: 308-311

\section{INTRODUCTION}

Choosing Wisely Canada (CWC) aims to improve healthcare quality and delivery by reducing the burden of unnecessary testing, inappropriate treatments, and adverse outcomes for patients. Choosing Wisely recommendations are compiled into lists generated by medical societies in Canada to promote tangible ways for health providers to apply these principles in practice and begin conversations about overutilization in healthcare. As of January 2019, 49 medical societies had published a collective of more than 250 CWC recommendations. Despite the reflection of $\mathrm{CWC}$ principles in neurology education, guidelines, and practice, a CWC neurology list was lacking. The Canadian Neurological Society (CNS) approved the creation of a taskforce. Quantitative and qualitative methods were used to generate a CWC list on behalf of the CNS for both neurologist and non-neurologist physicians and trainees, beginning with reviewing Canadian neurology guidelines and American Choosing Wisely recommendations. This was pared down into a final list of seven recommendations and further refined with feedback from practicing neurologists.

\section{Method}

A task force was struck and followed the CWC outline for medical societies to generate a list of recommendations (Figure 1). The process began with careful consideration of each of the 45 Choosing Wisely recommendations published by the American Board of Internal Medicine within the realm of neurosciences from numerous American medical societies (American Epilepsy Society, American Association of Neuromuscular and Electrodiagnostic Medicine, American Academy of Nursing, American College of Emergency Physicians, American Geriatrics Society,

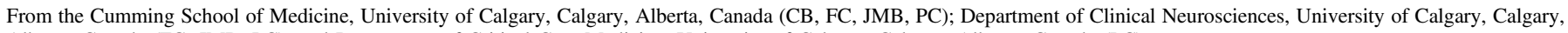
Alberta, Canada (FC, JMB, PC); and Department of Critical Care Medicine, University of Calgary, Calgary, Alberta, Canada (PC)

Received May 25, 2020. Final Revisions Submitted September 10, 2020. Date of Acceptance September 14, 2020.

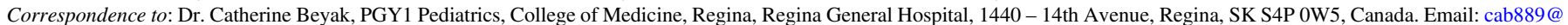
usask.ca 
American Academy of Neurology, and American Academy of Pediatrics). Each recommendation was evaluated based on its applicability to Canadian neurology practice by generalists and specialists. Ten of the 45 neuroscience recommendations were deemed to be both relevant and important for Canadian neurosciences, with minimal overlap with neurology recommendations addressed in other pre-existing CWC lists (Figure 2). The supporting literature was reviewed, and the quality therein was assessed for each of the 10 proposed recommendations. Readers will find references in Figure 2. The recommendations were altered slightly to align with current Canadian neurology guidelines, high-quality reviews, and meta-analyses.

The 10 proposed recommendations were sent to all CNS board members for approval; these recommendations were reviewed and ranked by the CNS members, including neurologists, fellows, and residents. CNS members at large were surveyed regarding their ranking preferences and relevant feedback. The average ranking for each recommendation was scored from which a list of the top five recommendations was compiled.

\begin{tabular}{l}
\hline Formed task force August 2018 \\
\hline Reviewed US Choosing Wisely Neurosciences Recommendations \\
\hline Reviewed evidence and guidelines in Canadian practice \\
\hline Compiled list of 10 recommendations \\
\hline Sent 10 recommendations to board members of each society in the CNS for approval \\
Sent survey to CNS members for ranking of recommendations and comments February 2019 \\
\hline Survey results compiled June 2019 \\
\hline List tailored by Choosing Wisely Canada October 2019 \\
\hline List finalized by December 2019 \\
\hline Neurology List published and distributed by CWC January 2020
\end{tabular}

Figure 1: List generation process and stakeholder input.

\section{ReSUlTS}

Survey participants were asked to rank the proposed recommendations from 1 to 10 with the aim of producing a top five list (Figure 3). This quantitative data was combined with qualitative feedback from neurologists across Canada through comments in the survey and verbal input from presentations at conferences. The list of the top five was proposed to CWC who recommended expansion of two of the proposed recommendations (Figure 3: numbers 4 and 5). The list was then expanded into seven recommendations. This allowed for more emphasis for certain points including not using opioids for migraine to fit with CWC's "Opioid wisely" campaign, which was made separate from butalbitol, butorphenol, and ergotamines for migraines. Additionally, the separation of investigations for minor head trauma and syncope emphasizes that computed tomography should be considered with a validated screening tool for minor trauma which is separate from neuroimaging and electroencephalogram use for syncope.

\section{Discussion}

The list was sent to CWC following CNS membership input and altered for clarity, with feedback from CWC champions from other medical societies. The list was posted and publicized by CWC in January 2020 (Figure 4). Two goals were met. Firstly, to demonstrate support for resource stewardship and patient safety principles in neurology by promoting only what is necessary. Secondly, to generate a usable, evidence-based list of recommendations for physicians, including neurologists and non-neurologists to guide management. Through reducing unnecessary testing and treatments, healthcare spending can be appropriately allocated for evidence-based practices which can help patients and the system at large.

The CWC list might not address specific individual patient complexities and is it not meant to replace clinical judgment. Rather, it provides guidance to the health practitioners. It may

1. Don't treat women of childbearing potential with valproic acid if other effective treatments are available $\mathrm{e}^{1,2,3,4}$

2. Don't routinely perform brain imaging after acute seizure in patients with established epilepsy $5,6,7,8,9$

3. Don't choose opioids, narcotics, or cannabinoids as the first choice of treatment for neuropathic pain ${ }^{10,11}$

4. Don't order neuroimaging or EEG in asymptomatic adult patients in the emergency department with syncope, insignificant trauma and a normal neurological evaluation ${ }^{12,13,14}$

5. Don't prescribe cholinesterase inhibitors or memantine for dementia without periodic assessment for perceived cognitive benefits and adverse effects $15,16,17,18,19$

6. Don't recommend CEA for asymptomatic carotid stenosis unless the complication rate is low $(<3 \%)^{20,21,22}$

7. Don't prescribe interferon-beta or glatiramer acetate to patients with disability from progressive, non-relapsing forms of multiple sclerosis ${ }^{23,24}$

8. Don't use opioids, butalbital, butorphanol, or ergotamine treatment for migraine except as a last resort ${ }^{25,26}$

9. Don't order neuroimaging (CT, MRI) in a child with simple febrile seizure $\mathrm{e}^{27,28,29,30}$

10. Don't order an EEG on neurologically healthy children who have a simple febrile seizure ${ }^{27,28,29,30,31}$

Figure 2: Preliminary list of 10 recommendations adapted from American Choosing Wisely Neurosciences recommendations. ${ }^{-31}$ 


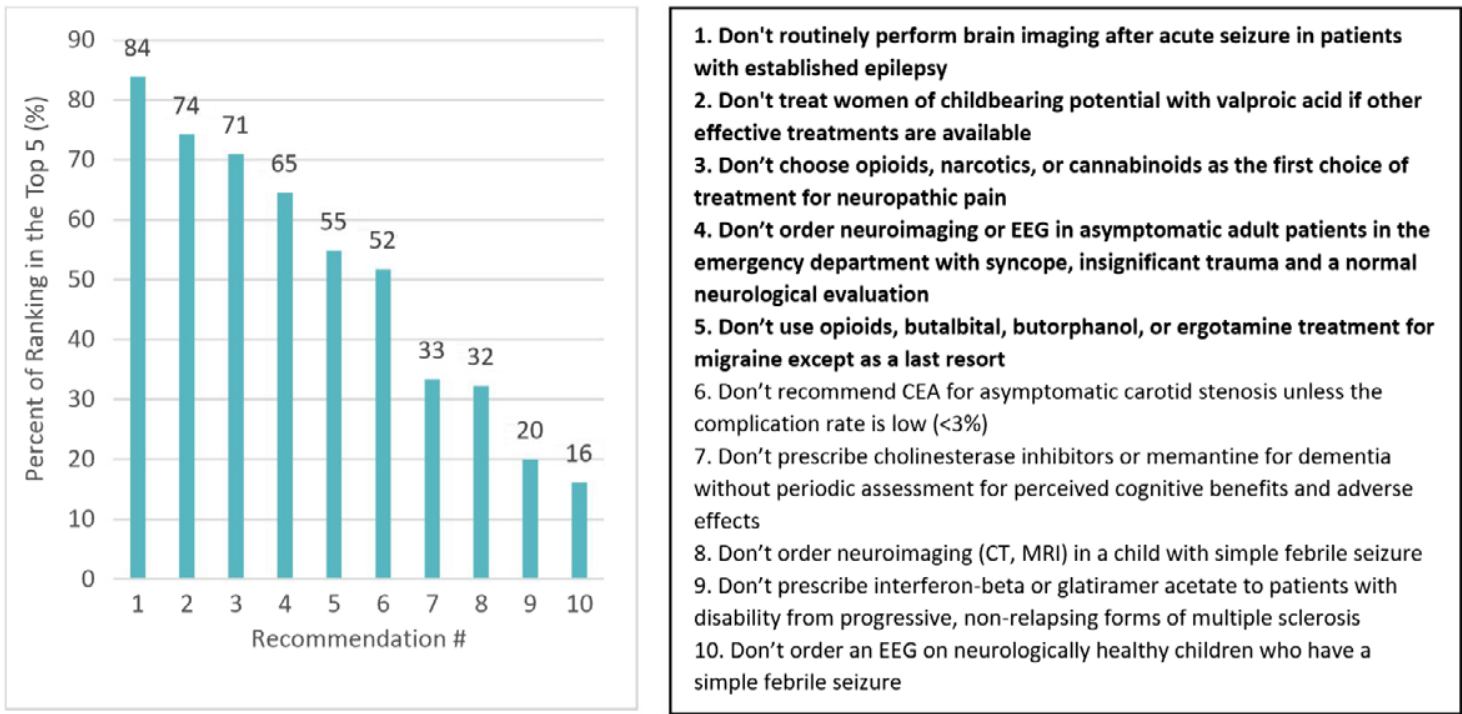

Figure 3: Percentage of each proposed recommendation ranking within the top five by CNS members via online survey $(\mathrm{n}=31)$. Corresponding numbered list of recommendations on the right which emphasizes the top five that were chosen in bold.

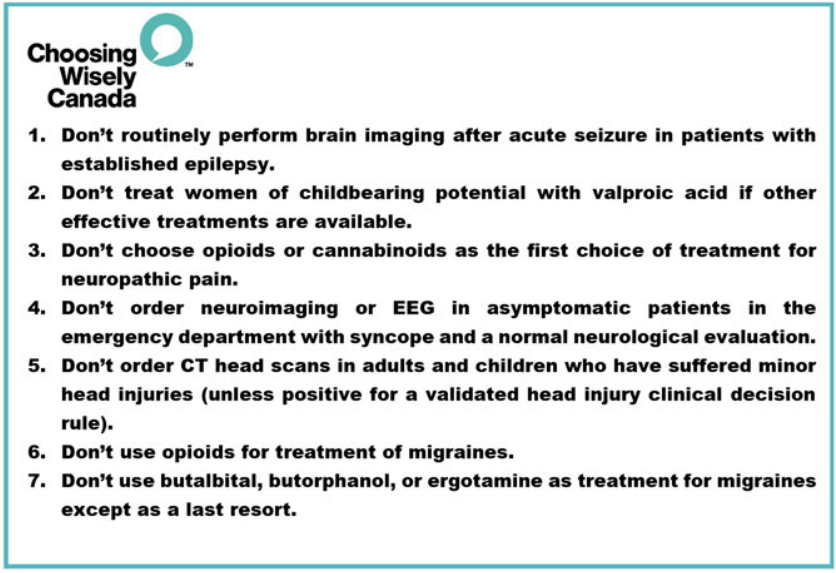

Figure 4: Final list of seven published recommendations in Choosing Wisely Canada January 2020. ${ }^{31}$

serve as a reminder to consider whether imaging, tests, or treatments lacking supportive evidence should be ordered. This list will not replace individual decision-making and careful consideration of each patient will still be necessary. On the other hand, it may help patients in understanding that oftentimes, doing less can lead to better outcomes. Additionally, a succinct list of seven recommendations is simpler to generate and disseminate, but it cannot be all encompassing; there are likely more areas of overuse in clinical neurology that are not addressed in this list. It will also require updates if more or contradicting evidence becomes available. Input from stakeholders was sought to ensure that the most important principles were conveyed in the list on behalf of the CNS. This short list should be one of the small steps in propelling resource stewardship in neurology forward.

\section{Conclusion}

Participating in the CWC national campaign is an important health advocacy task that has been undertaken by the CNS. By providing an outline on how the list was generated, it is hoped a review can be conducted at regular intervals to improve care for neurology patients while reducing unnecessary tests and treatments. This list can adapt over time, as treatment paradigms change and arise in neurology.

\section{ACKNowledgments}

The authors would like to acknowledge members of the CNS who participated in the survey. The authors would like to acknowledge Joanna Wong and Wendy Levinson at CWC for their guidance.

\section{Disclosures}

Dr. Costello has received consultancy Honoria from Roche, Alexion. The other authors have no conflicts of interest to declare.

\section{Statement of Authorship}

CB: conception, data collection, data analysis and interpretation, drafting the article, and final approval of the version to be published. FC: critical revision of the article and final approval of the version to be published. JMB: critical revision of the article and final approval of the version to be published. PC: design of the work, critical revision of the article, final approval of the version to be published.

\section{REFERENCES}

1. Bansal R, Jain G, Kharbanda PS, Goyal MK, Suri V. Maternal and neonatal complications during pregnancy in women with epilepsy. Int J Epilepsy 2016;3(2):80-85.

2. Campbell E, Kennedy F, Russell A, et al. Malformation risks of antiepileptic drug monotherapies in pregnancy: updated results from the UK and Ireland Epilepsy and Pregnancy Registers. J Neurol NeurosurgPsychiatry 2014;85(9):1029-34.

3. Hernández-Díaz S, Smith CR, Shen A, et al. for the North American AED Pregnancy Registry. Comparative safety of antiepileptic drugs during pregnancy. Neurology 2012;78(21):1692-9. 
4. Voinescu PE, Pennell PB. Management of epilepsy during pregnancy. Exp Rev Neurotherapeutics 2015;15(10):1171-87.

5. Cendes F, Theodore WH, Brinkmann BH, Sulc V, Cascino GD. Neuroimaging of epilepsy. Handbook Clin Neurol 2016;136: 985-1014.

6. Commission on Neuroimaging of the International League Against Epilepsy. Recommendations for neuroimaging of patients with epilepsy. Epilepsia 1997;38(11):1255-6.

7. Epilepsy Implementation Task Force. Provincial Guidelines for the Management of Epilepsy in Adults and Children. Critical Care Services Ontario. December 2014. https://www.critical careontario.ca/EN/Epilepsy Guideline Series/Provincial Guidelines for Management of Epilepsy in Adults and Children_January 2015.pdf; last accessed 28 October 2018.

8. Harden CL, Huff JS, Schwartz TH, et al. Reassessment: neuroimaging in the emergency patient presenting with seizure (an evidence-based review). Report of the Therapeutics and Technology Assessment Subcommittee of the American Academy of Neurology. Neurology 2007;69(18):1772-80.

9. Lapalme-Remis S, Cascino GD. Imaging for adults with seizures and epilepsy. Continuum (Minneap Minn). 2016;22(5):1451-1479.

10. Finnerup NB, Attal, N, Haroutounian S, et al. Pharmacotherapy for neuropathic pain in adults: a systematic review and meta-analysis. Lancet Neurol. 2015;14(2):162-73.

11. Moulin DE, Boulanger A, Clark AJ, et al. Pharmacological management of chronic neuropathic pain: revised consensus statement from the Canadian Pain Society. Pain Res Manag 2014;19(6): 328-35.

12. İdil H, Yilmaz K. Diagnostic yield of neuroimaging in syncope patients without high-risk symptoms indicating neurological syncope. Am J Emerg Med. 2018. pii:S0735-6757(18)30410-8.

13. Sanatani S, Chau V, Fournier A, Dixon A, Blondin R, Sheldon RS. Canadian Cardiovascular Society and Canadian Pediatric Cardiology Association position statement on the approach to syncope in the pediatric patient. Can J Cardiol. 2017;33(2):189-198.

14. Shenk MER, Anilkumar A. Syncope in children: etiology, positive and negative predictors, and utilization and utility of diagnostic testing. Neurology 2017;88(16):P3.204.

15. Moore A, Patterson C, Lee L, Vedel I, Bergman H. Fourth Canadian consensus conference on the diagnosis and treatment of dementia: recommendations for family physicians. Can Family Phys. 2014; 60(5):433-438.

16. Doody RS, Stevens JC, Beck C, et al. Practice parameter: management of dementia (an evidence based review). Report of the Quality Standards Subcommittee of the American Academy of Neurology. Neurology 2001;56(9):1154.

17. Raina P, Santaguida P, Ismaila A, et al. Effectiveness of cholinesterase inhibitors and memantine for treating dementia: evidence review for a clinical practice guideline. Ann Intern Med. 2008; 148(5):379-97.
18. Reeve E, Farrell B, Thompson W, et al. Evidence-based Clinical Practice Guideline for Deprescribing Cholinesterase Inhibitors and Memantine: Recommendations. Sydney: The University of Sydney; 2018.

19. Toward Optimized Practice. Cognitive Impairment Part 2: Diagnosis to Management Clinical Practice Guideline [Internet]. February 2017. https://actt.albertadoctors.org/CPGs/Lists/CPGDocument List/Cogn-Imp-2-Diagnosis-to-Management.pdf; last accessed 28 October 2018.

20. Goldstein LB, Bushnell CD, Adams RJ, et al. Guidelines for the primary prevention of stroke: a guideline for healthcare professionals from the American Heart Association/American Stroke Association. Stroke 2011;42(2):517-84.

21. LeFevre ML for the US Preventative Services Task Force. Screening for asymptomatic carotid artery stenosis: U.S. preventive services task force recommendation statement. Ann Intern Med 2014; 161:356-362.

22. Wein TM, Lindsay MP, Côté R, et al. Canadian stroke best practice recommendations: secondary prevention of stroke, sixth edition practice guidelines, update 2017. Int J Stroke 2017;13(4):420-443.

23. Rae-Grant A, Day GS, Marrie RA, et al. Practice guideline: diseasemodifying therapies for adults with multiple sclerosis. Neurology 2018;90(17):777-88.

24. Willis MA, Fox RJ. Multiple sclerosis and other demyelinating diseases: progressive multiple sclerosis. Continuum. 2016;22(3): 785-798.

25. Tepper S, Spears RC. Acute treatment of migraine. Neurolog Clin. 2009;27(2):417-27.

26. Worthington I, Pringsheim T, Gawel MJ, et al. Canadian headache society guideline: acute drug therapy for migraine headache. Can J Neurolog Sci/J Canadien Des Sci Neurologiques 2013;40(S3): S1-S3.

27. Guidelines and Protocols Advisory Committee on behalf of the Medical Services Commission. Febrile Seizures [Internet]. September 2010. http://www.24hmb.com/voimages/web_image// upload/file/20140628/69431403922851420.pdf; last accessed 28 October 2018.

28. Ma L, Mccauley SO. Management of pediatric febrile seizures. J Nurse Pract. 2018;14(2):74-80.

29. Provisional Committee on Quality Improvement, Subcommittee on febrile seizures. practice parameter: the neurodiagnostic evaluation of the child with a first simple febrile seizure. Pediatrics 1996;97(5):769-772.

30. Srinivasan J, Wallace KA, Scheffer IE, et al. Febrile seizures. Aust Family Phys. 2005;34(12):1021-5.

31. Harini $C$, Nagarajan E, Kimia AA, et al. Utility of initial EEG in first complex febrile seizure. Epilepsy Behav. 2015;52(Pt A):200-4.

32. Choosing Wisely Canada. (2015). Neurology recommendations retrieved from https://choosingwiselycanada.org/; last accessed 28 January 2020. 